\title{
Percutaneous balloon dilatation in congenital mitral
} stenosis

\author{
LUIS E ALDAY, ERNESTO JUANEDA \\ From the Department of Cardiology, Children's Hospital, and the Department of Paediatrics, National \\ University of Cordoba, Cordoba, Argentina
}

SUMMARY A three year old girl with severe congenital mitral stenosis was successfully treated by percutaneous balloon dilatation of the mitral valve. Cardiac catheterisation and cross sectional and Doppler echocardiography indicated that the orifice of the mitral valve had doubled in area. A small atrial septal defect was found at follow up cardiac catheterisation and angiography.

Balloon dilatation of the mitral valve is a reasonable alternative to surgical treatment for typical congenital mitral stenosis even in young children.

Since Kan et al first advocated the use of percutaneous balloon dilatation for the treatment of congenital pulmonary valve stenosis, ${ }^{1}$ the procedure has been widely applied in this ${ }^{2-4}$ and in other obstructive lesions such as aortic valve stenosis, ${ }^{5}$ coarctation of the aorta, ${ }^{6}$ peripheral pulmonary stenoses, $^{7}$ and obstructed veins. ${ }^{8}$ Balloon angioplasty has also been successful as a treatment for rheumatic mitral valve stenosis in older children, young adults, and adults..$^{9-12}$ The technique was also used in an adolescent with congenital mitral valve stenosis. ${ }^{13}$ We report a case of successful dilatation of the mitral valve by percutaneous balloon dilatation in a young child.

\section{Case report}

A girl aged 3 years and 4 months with a history of poor exercise tolerance and failure to thrive was referred for cardiac evaluation and treatment. On physical examination she was undernourished (weight $8.5 \mathrm{~kg}$, below the third percentile) and the findings at auscultation were typical of severe mitral stenosis. The rest of the physical examination was unremarkable. Chest $x$ rays showed moderate cardiomegaly with a cardiothoracic ratio of 0.58. There was left atrial and right ventricular enlarge-

Requests for reprints to Dr Luis E Alday, Department of Cardiology, Hospital de Niños, Corrientes 643, 5000 Cordoba, Argentina. ment and signs of pulmonary venous hypertension. The electrocardiogram had a mean QRS axis of $+100^{\circ}$ in the frontal plane and there was evidence of left atrial enlargement and right ventricular hypertrophy. Cross sectional echocardiographic and Doppler examination revealed mitral stenosis with a valve area of $1.10 \mathrm{~cm}^{2}$. After obtaining informed consent from the parents, we performed combined percutaneous cardiac catheterisation and selective cineangiocardiography followed by mitral valve dilatation from the right femoral vein and the left femoral artery under general anaesthesia. The haemodynamic findings showed moderately severe pulmonary hypertension and a $7 \mathrm{~mm} \mathrm{Hg}$ gradient across the mitral valve (table). The left ventricular cineangiogram disclosed severe mitral stenosis and slight mitral incompetence. Mild tricuspid regurgitation and considerable enlargement of the left atrium with a prolonged washout time in the laevophase were seen on right ventricular cineangiography.

We used the following technique for the mitral valve dilatation. The venous catheter was replaced by a number 8.5 French transseptal left heart catheter (USCI) which was advanced to the right atrium. A Brockenbrough needle was introduced into the catheter and the atrial septum was punctured. The catheter was advanced over the needle into the left atrium and the needle was withdrawn. We then gave 100 units of heparin per kg. After the left atrial pressure had been measured the catheter was advanced 
Table Cardiac catheterisation data before, immediately after, and one month after mitral angioplasty

\begin{tabular}{|c|c|c|c|c|}
\hline & Before & After & 1 month & $c$ \\
\hline
\end{tabular}

Numbers in parentheses are mean pressures. Qp, pulmonary flow; Qs, systemic flow; Rp, total pulmonary resistance; Rs, systeric resistance. * Wood units.

through the mitral valve into the left ventricle. A 0.038 inch Teflon coated guide wire $(180 \mathrm{~cm}$ long) (Cook) was then placed in the left ventricle through the transseptal catheter. The guide wire was looped within the ventricular cavity and advanced through the aortic valve to the ascending aorta. The transt septal catheter was removed and a $12 \mathrm{~mm}$ balloon angioplasty catheter number 9 French (Medi-Tech)
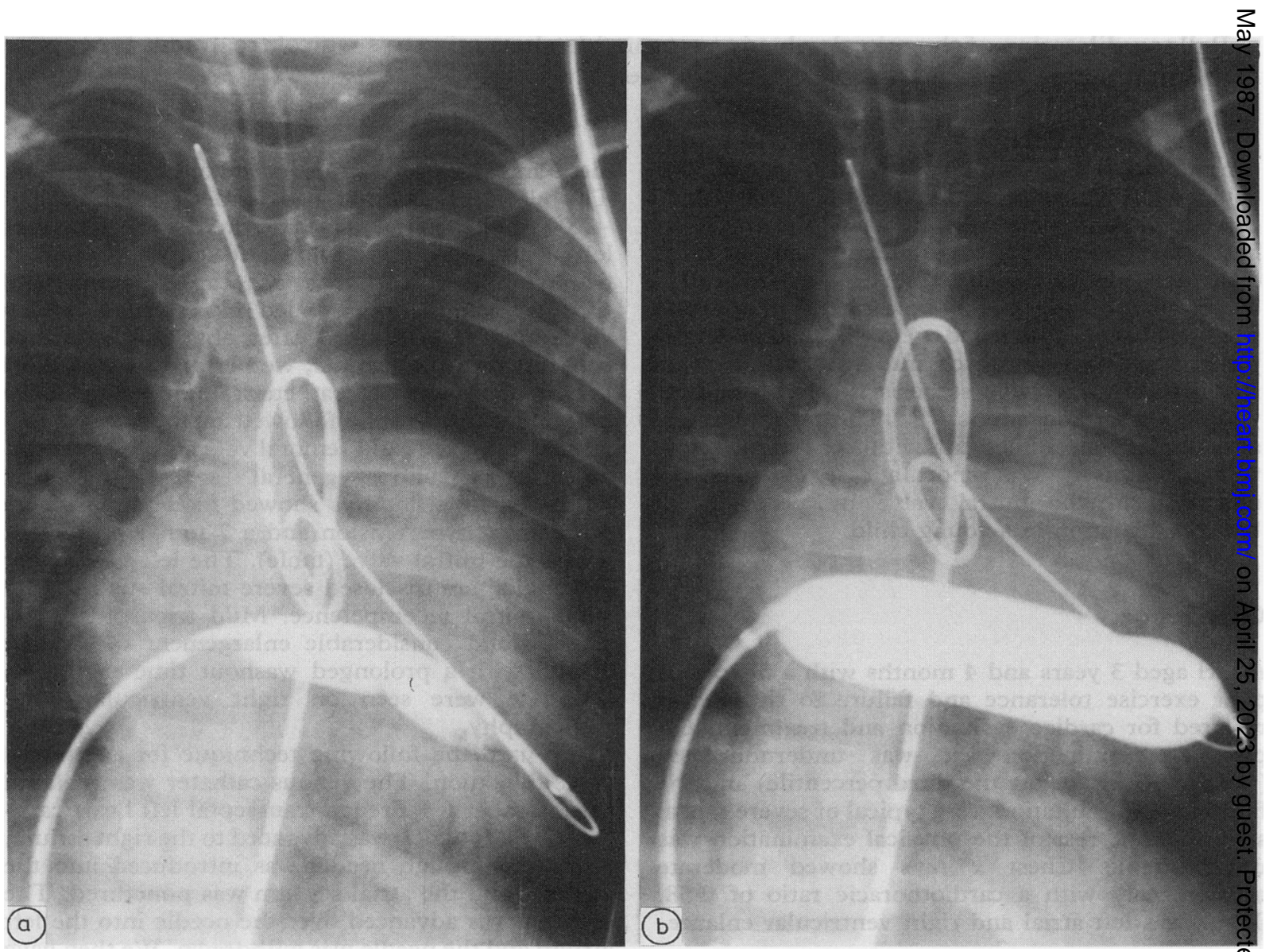

Fig 1 (a) $X$ ray of the $12 \mathrm{~mm}$ balloon catheter placed across the mitral orifice half inflated and showing an indentation in the area of the stenotic mitral valve. (b) $X$ ray of the $18 \mathrm{~mm}$ balloon catheter distended at full pressure. 


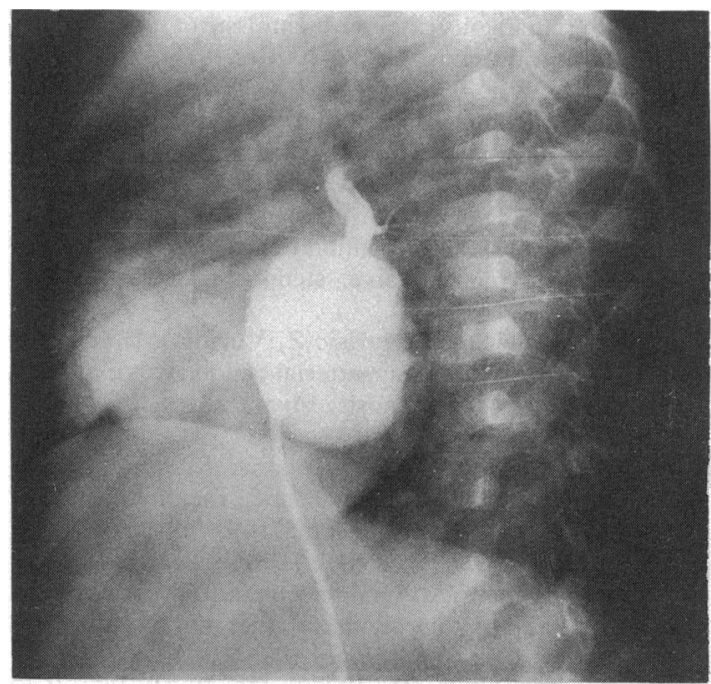

Fig 2 Left atrial angiogram in the four chamber view showing an enlarged left atrium and a small atrial septal defect.

was advanced over the guide wire and placed across the mitral valve orifice (fig la). The balloon was then inflated with diluted contrast medium at $354 \mathrm{kN} / \mathrm{m}^{2}$ ( $3.5 \mathrm{~atm})$ pressure for three 10 second periods. The procedure was repeated with an $18 \mathrm{~mm}$ angioplasty catheter (fig 1b). After the balloon catheter had been removed, the transseptal catheter was reintroduced and the pressure measurements were repeated (table). The arterial catheter, which had been left at aortic valve level for continuous recording of systemic pressure, was passed in the left ventricle and cineangiography was repeated.

After balloon dilatation the transmitral valve gradient decreased to $1.5 \mathrm{~mm} \mathrm{Hg}$. The left ventricular cineangiogram showed mild mitral regurgitation equivalent to that found at the previous angiographic examination. The whole procedure took one hour and 40 minutes and there were no complications. The patient was discharged from hospital two days later.

Physical examination after dilatation disclosed a much softer mid-diastolic rumble in the area of the mitral valve. There had been no murmur immediately after dilatation. Cross sectional and Doppler echocardiographic examinations were repeated a week later and they indicated an increase of the mitral valve orifice to $2.34 \mathrm{~cm}^{2}$. At follow up the patient's exercise tolerance was considerably improved. Cardiac catheterisation performed a month after angioplasty showed a decline in pulmonary artery pressure and resistance and a $3 \mathrm{~mm}$ $\mathrm{Hg}$ transmitral gradient (table). The mitral valve area had apparently doubled and there was evidence of a small atrial septal defect both by oximetry and by left atrial cineangiography (fig 2 ).

\section{Discussion}

Balloon dilatation of the mitral valve is an effective method for relieving stenosis of the rheumatic mitral valve. ${ }^{9-12}$ It has been used in older children and adults and even in elderly patients with calcific mitral stenosis ${ }^{14}{ }^{15}$; no serious complications have been reported. When balloon angioplasty of the mitral valve was attempted in two patients with congenital mitral stenosis it was successful in the adolescent patient but failed in the 2 year old boy who also had associated anomalies. ${ }^{13}$

Despite the small size of our patient, balloon dilatation of the stenotic mitral valve was achieved without complication and the procedure was not lengthy. Haemodynamic measurements and echocardiography and Doppler studies both showed that the mitral valve orifice had doubled in area after dilatation.

The technique we used differed only slightly from that described by Lock $e t$ al and Kveselis et al..$^{913}$ As reported by Lock et al, ${ }^{9}$ the distal end of the exchange guide wire was placed in the ascending aorta to facilitate replacement of the catheter. We did not use a Swan-Ganz catheter to traverse the aortic valve, however; we accomplished this objective by looping the guide wire within the left ventricle. A $12 \mathrm{~mm}$ balloon catheter was used to facilitate the subsequent passage of the larger $18 \mathrm{~mm}$ balloon across the atrial septum. As was also seen in one of Lock's patients, ${ }^{9}$ we found a small residual atrial septal defect at follow up catheterisation. Nevertheless, there was clinical and haemodynamic improvement after dilatation. To avoid creating an atrial septal defect after transseptal mitral valve dilatation, Babic et al performed mitral dilatation by introducing the balloon catheter from the arterial side. ${ }^{12}$ All their patients were adults, however, and it is unlikely that this technique could be applied in young children.

Congenital mitral stenosis accounts for only $0 \cdot 2 \%$ of all congenital heart defects. ${ }^{16}$ Four anatomical types have been described. ${ }^{17}$ Typical mitral stenosis is found in nearly $50 \%$ of patients. In this type the leaflets are thickened and are fused and the chordae shortened. Other types are mitral stenosis as a component of the hypoplastic left heart syndrome, the supravalvar mitral ring, and the parachute mitral valve. We think that for typical mitral stenosis balloon dilatation is a reasonable alternative to surgical treatment, even in young children. 
References

1 Kan JS, White RI Jr, Mitchell SE, Gardner TJ. Percutaneous balloon valvuloplasty: a new method for treating congenital pulmonary valve stenosis. $N$ Engl f Med 1982;307:540-2.

2 Lababidi $\mathrm{Z}, \mathrm{Wu}$ J. Percutaneous balloon valvuloplasty. Am $\mathcal{f}$ Cardiol 1983;52:560-2.

3 Rocchini AP, Kveselis DA, Crowley D, Dick M, Rosenthal A. Percutaneous balloon valvuloplasty for treatment of congenital pulmonary valve stenosis in children. I Am Coll Cardiol 1984;3:1005-12.

4 Tynan M, Baker EJ, Rohmer J, et al. Percutaneous balloon pulmonary valvuloplasty. Br Heart $\mathcal{F} 1985$; 53:520-4.

5 Lababidi Z, Wu JR, Walls TJ. Percutaneous balloon aortic valvuloplasty; results in 23 patients. $A m \mathcal{F}$ Cardiol 1984;53:194-7.

6 Lock JE, Bass JL, Amplatz K, Fuhrman BP, Castaneda-Zuniga WR. Balloon dilatation angioplasty of coarctations in infants and children. Circulation 1983;68:109-16.

7 Lock JE, Castaneda-Zuniga WR, Fuhrman BP, Bass JL. Balloon dilatation angioplasty of hypoplastic and stenotic pulmonary arteries. Circulation 1983;67: 962-7.

8 Lock JE, Bass JL, Castaneda-Zuniga W, Fuhrman BP, Rashkind WJ, Lucas RV Jr. Dilation angioplasty of congenital or operative narrowing of venous channels. Circulation 1984;70:457-64.

9 Lock JE, Khalilullah M, Shrivastava S, Bahl V, Keane
JF. Percutaneous catheter commissurotomy in rheumatic mitral stenosis. $N$ Engl $J$ Med 1985;313:1515-8. c

10 Inowe $K$, Owaki T, Nakamura T, Kitamura F, Miyamoto $\mathrm{N}$. Clinical application of transvenous mitral commissurotomy by a new balloon catheter. $J$ Thorac Cardiovasc Surg 1984;87:394-402.

11 Zaibag MA, Ribeiro PA, Kasab SA, Faghi MRA. Percutaneous double-balloon mitral valvotomy for rheumatic mitral valve stenosis. Lancet 1986;i: 757-61.

12 Babic UU, Pejcic P, Djurisic Z, Vucinic M, Grujicic SM. Percutaneous transarterial balloon valvuloplasty for mitral valve stenosis. Am J Cardiol 1986;57: 1101-4.

13 Kveselis DA, Rocchini AP, Beekman R, et al. Balloon angioplasty for congenital and rheumatic mitral stenosis. Am J Cardiol 1986;57:348-50.

14 McKay RG, Lock JE, Keane JF, Safian RD, Aroesty JM, Grossman W. Percutaneous mitral valvuloplasty in an adult patient with calcific rheumatic mitral stenosis. J Am Coll Cardiol 1986;7:1410-5.

15 Palacios IF, Lock JE, Keane JF, Block PC. Percutaneous transvenous balloon valvotomy in a patient with severe calcific mitral stenosis. J Am Coll Cardiol 1986;7:1416-9.

16 Keith JD. Prevalence, incidence and epidemiology. In: Keith JD, Rowe RD, Vlad P. Heart disease in infancy and childhood. New York: Macmillan, 1978:6.

17 Ruckman RN, Van Praagh R. Anatomic types of congenital mitral stenosis: report of 49 autopsy cases with considerations of diagnostic and surgical implications. Am J Cardiol 1978;42:592-601. 